plane. Transverse cerebellar diameter (TCD), 4th ventricle width (4VW) and length (4VL) were assessed via mastoid fontanelle.

Results Sector probe gave significantly smaller measurement results than convex transducer. Left side measurements were significantly greater than right side ones. VI, VW, BW, TCD and 4VW were dependent on birth weight, birth length, head circumference and gestational age. ACSP, FHW, TOD and JR were independent of those factors. No relationships were found between gender and measured diameters or calculated ratios.

Conclusions Reference values for cranial measurements, ER and JR were determined for examined population of premature newborns. Described indices may be useful for everyday clinical practice in neonatal units.

\section{ABNORMAL HEART RATE CHARACTERISTICS ARE ASSOCIATED WITH ABNORMAL BRAIN ULTRASOUND AND MRI IN EXTREMELY LOW BIRTH WEIGHT INFANTS}

doi:10.1136/archdischild-2012-302724.1066

${ }^{1} \mathrm{~K}$ Fairchild, 'R Sinkin, ${ }^{2} \mathrm{~J}$ Matsumoto, 'F Davalian, ${ }^{3} \mathrm{D}$ Lake, ${ }^{3} \mathrm{JR}$ Moorman, ${ }^{1} \mathrm{~J}$ Blackman. 'Pediatrics; ${ }^{2}$ Radiology; ${ }^{3}$ Medicine, University of Virginia, Charlottesville, VA, USA

Background and Aim Brain injury may lead to autonomic nervous system dysfunction reflected by abnormal heart rate characteristics (HRC). A HRC monitor was developed to analyze heart rate variability and decelerations and predict catastrophic illness in NICU patients (HeRO monitor). We tested the hypothesis that the HRC index would be abnormally high in preterm infants with abnormal brain ultrasound and MRI.

Methods We collected HRC data on extremely low birthweight infants who underwent brain MRI as part of a study of neurodevelopmental outcomes. Brain ultrasounds (US) were performed in the first week and as clinically indicated, and brain MRI was performed near discharge. US were scored as normal $/ \mathrm{mild}$ (including grades 1-2 IVH) and moderate/severe (grades $3-4$ IVH or cystic periventricular leukomalacia). MRI was scored $0-3$ for gray and white matter injury.

Results 45 ELBW infants with MRI performed had HRC data available. MRI was classified as 0 (normal, $n=22$ ), 1 (mild, $n=14$ ), 2 (moderate, $\mathrm{n}=5$ ) or 3 (severely abnormal, $\mathrm{n}=4$ ) and US as normal/ mild $(n=36)$ or moderate/severe $(n=9)$. Average HRC index in the first 28 days after birth (aHRC28) was highly correlated with severity of abnormal brain US and MRI. aHRC28 for patients with nor$\mathrm{mal} / \mathrm{mild}$ US abnormalities was $1.37 \pm 0.48$ (mean $\pm \mathrm{SD}$ ) and with moderate/severe $2.53 \pm 0.69$ ( $\mathrm{p}<0.001)$. For MRI, aHRC28 for patients with classes $0-3$ was $1.24 \pm 0.44,1.59 \pm 0.53,2.49 \pm 0.68^{*}, 2.72 \pm 0.82 *$, $\left({ }^{*} \mathrm{p}<0.001\right.$ versus class 0$)$. Differences persisted after adjustment for gestational age and birthweight.

Conclusion HRC monitoring may be a useful adjunct test for severity of brain injury in NICU patients.

\section{INITIAL EXPERIENCE OF EFFECT OF SELECTIVE HEAD COOLING IN NORMOTHERMIC AND HYPOTHERMIC INFANTS}

doi:10.1136/archdischild-2012-302724.1067

'AN Sofijanova, ${ }^{1} \mathrm{OV}$ Jordanova, ${ }^{2} \mathrm{~K}$ Piperkova. ${ }^{1}$ Neonatal and Pediatric Intensive Care; ${ }^{2}$ Department of Neonatology, University Children's Hospital, Skopje, FYR Macedonia

The Aim of this Study To evaluate the effect of selective head cooling (introduced 3 months ago in the Neonatal Intensive Care Unit at the University Children's Hospital in Skopje-Macedonia) on S100 B protein levels, previously measured only in normothermic infants after perinatal asphyxia and the preliminary neurodevelopment outcome at the age of 3 months.

Methods All risk neonates with severe asphyxia admitted within $24 \mathrm{~h}$ of injury were eligible for inclusion in the study. One serum blood sample was obtained from each patient the first day of admission, and $48 \mathrm{~h}$ and $72 \mathrm{~h}$ hours after admission. S100B levels were measured using ECLIA method (Electro-Chemil-Luminiscence Immuno Assay-Elecsys 2010-Roche Diagnostic).

Results The avarage serum S100B levels for the control group $(\mathrm{N}=48)$ was 0.12 microgL $(-1)$ (cut-off point). Serum S100B levels were grossly elevated in both HT and NT groups of infants with asphyxia. The differences were statistically significant as follows: a) between the first (24h) and second (day 4) time interval significant at $\mathrm{p}<0.05 ; \mathrm{b}$ ) between the second (day 4) and third (day 7) time interval significant at $\mathrm{p}<0,005 ; \mathrm{c}$ ) between the first $(24 \mathrm{~h})$ and third (day 7) time interval significant at $p \leq 0,001$. Serum $S 100 B$ values were lower in HT (selective head cooling infants) compared to NT infants ( $\mathrm{p}=0.049$ at 48 hours).

Conclusion Serum S100B levels were lower in the HT group after $72 \mathrm{~h}$, and strongly correlated with the neurodevelopment impairment. S100B levels are highly elevated following asphyxia. Serum S100B levels are lowering in the HT and strongly correlate with the early neurodevelopment outcome.

\section{CAN LOSS OF SLEEP-AWAKE CYCLICITY AT AEEG PREDICT POSTHEMORRHAGIC HYDROCEPHALUS IN PRETERM INFANTS WITH INTRAVENTRICULAR HEMORRHAGE?}

doi:10.1136/archdischild-2012-302724.1068

${ }^{1}$ A Scoppa, ${ }^{1} \mathrm{~N}$ Pozzi, ${ }^{2} \mathrm{C}$ Pallante, 'F Boffa, 'L Orfeo. 'NICU AND PICU, 'G. Rummo' Hospital, Benevento; ${ }^{2}$ A. Cardarelli Hospital, Neaples, Italy

Background and Aim Intraventricular hemorrhage (IVH) is the most common brain injury in preterm infants. Among infants with IVH $30 \%$ develops posthemorrhagic hydrocephalus (PPH). Actually there is no predicting factor for the developing of $\mathrm{PPH}$. We observed if loss of sleep-awake cyclicity, at aEEG evaluation, is predictive for $\mathrm{PPH}$.

Methods 6 preterms of gestational age between 25 and 30 weeks were detected for IVH (II degree to IPH) at cerebral ultrasonography. Cerebral background activity was continuously performed by CFM (Brainz US)

Results Sleep-awake ciclicity was observed in all 6 infants in the first 24 hours after the detection of IVH. But in 2 of these we noted the loss of cyclicity few days after the diagnosis of the bleeding. These 2 patients developed posthemorrhagic hydrocephalus whereas the other 4 infants didn't develop PPH.

Conclusions Loss of sleep-awake cyclicity, at aEEG, has a high positive predictive value for the developing of $\mathrm{PPH}$ in preterm infants with IVH; therefore study of cerebral background activity and in particular of sleep-awake cyclicity can be used as a early prognostic tools in patients at risk of $\mathrm{PPH}$.

\section{DOES CEREBRAL OXYGENATION AID IN OUTCOME PREDICTION IN ASPHYXIATED NEWBORNS SUBMITTED TO HYPOTHERMIA?}

doi:10.1136/archdischild-2012-302724.1069

P Costa, I Sampaio, K Cardoso, C Moniz, A Graça. Neonatology, Hospital de Santa Maria, CHLN, Lisbon, Portugal

Background and Aims Neurological outcome in asphyxiated newborns submitted to hypothermia is being predicted by aEEG and MRI. The aim of this study was to assess the value of regional cerebral oxygen saturation $\left(\mathrm{rSO}_{2}\right)$ in early outcome prediction and its relation with aEEG and brain MRI

Methods $\mathrm{rSO}_{2}$ was measured by NIRS INVOS monitor. Newborns were simultaneously monitored with aEEG during hypothermia and rewarming period. Values of $\mathrm{rSO}_{2}$ were analyzed in three groups of predicted outcome (normal, intermediate or abnormal) according 